\title{
Review
}

\section{The Psychosocial Impact of COVID-19 on Older Adults with Cancer: A Rapid Review}

\author{
Ridhi Verma ${ }^{1}$ (D) Heather M. Kilgour ${ }^{2}$ and Kristen R. Haase ${ }^{2, *(\mathbb{D})}$ \\ 1 School of Healthcare Sciences, Cardiff University, Cardiff CF10 3AT, UK; ridhiverma.in@gmail.com \\ 2 School of Nursing, The University of British Columbia, Vancouver Campus, T201-2211 Wesbrook Mall, \\ Vancouver, BC V6T 2B5, Canada; heather.kilgour@ubc.ca \\ * Correspondence: Kristen.haase@ubc.ca
}

\section{check for}

updates

Citation: Verma, R.; Kilgour, H.M.; Haase, K.R. The Psychosocial Impact of COVID-19 on Older Adults with Cancer: A Rapid Review. Curr. Oncol. 2022, 29, 589-601. https://doi.org/ 10.3390 /curroncol29020053

Received: 31 December 2021

Accepted: 22 January 2022

Published: 28 January 2022

Publisher's Note: MDPI stays neutral with regard to jurisdictional claims in published maps and institutional affiliations.

Copyright: (c) 2022 by the authors. Licensee MDPI, Basel, Switzerland. This article is an open access article distributed under the terms and conditions of the Creative Commons Attribution (CC BY) license (https:// creativecommons.org/licenses/by/ $4.0 /)$.

\begin{abstract}
Background: Older adults with cancer are amongst the most vulnerable population to be negatively impacted by COVID-19 due to their likelihood of comorbidities and compromised immune status. Considering the longevity of the pandemic, understanding the subjective perceptions and psychosocial concerns of this population may help ameliorate the psychological aftermath. In this review, we systematically analyze the literature surrounding the psychosocial impact and coping strategies among older adults with cancer within the context of COVID-19. Methods: We conducted a rapid review of literature following PRISMA guidelines between January 2020 to August 2021 using (1) MEDLINE, (2) Embase, (3) CINAHL, and (4) PsychINFO and keyword searches for "cancer" and "COVID-19" focused on adults 65 years or older. Results: Of the 6597 articles screened, 10 met the inclusion criteria. Based on the included articles, the psychosocial impact of COVID-19 was reported under four domains, (1) impact of COVID-19 on quality of life (QoL), (2) concerns related to COVID-19, (3) coping with the impact of COVID-19, and (4) recommendations for future care. Results pertaining to perceived quality of life were inconsistent across the included articles. The most common concerns related to: contracting COVID-19, survivorship transitions, and feelings of isolation. Coping strategies reported by older adults included: spiritual care, lived experience, acceptance, and positive reinterpretation. Conclusions: We found many psychosocial impacts of the pandemic on older adults with cancer. The findings from this review can inform interventions related to shared decision-making and tailored patient care in the future.
\end{abstract}

Keywords: cancer; older adults; mixed methods; COVID-19; quality of life; patient experience; qualitative methods

\section{Introduction}

Nearly two years into the COVID-19 pandemic, it continues to impact individuals' lives and health systems globally. This is particularly true of older adults with cancer, who may be among the most vulnerable to the effects of COVID-19 due to their immunocompromised status and increased presence of comorbidities [1-5]. Older adults diagnosed with both cancer and COVID-19 face increased mortality, hospitalization, and ICU admission [3-5]. In addition, the COVID-19 pandemic has caused significant disruption to the cancer care system, including a shift to virtual appointments, alternative treatment offerings, postponement of surveillance scans and surgeries, and diminished supportive care and survivorship services [6,7]. Older adult cancer survivors have described barriers to cancer treatment across the pandemic, including restricted attendance of caregivers at appointments, diminished access to healthcare services, and feeling less connected to their healthcare team $[8,9]$. Understanding the impact of these changes on the experiences of older adults with cancer is essential to learning how best to support older adults during this time.

Public health measures meant to diminish the spread of COVID-19, such as social distancing and stay-at-home mandates, have resulted in older adults spending more time 
alone, which may enhance feelings of isolation and loneliness. Recent reviews suggest that COVID-19 has created considerable anxiety, irritability, feelings of paranoia, and depression amongst community-dwelling older adults and people with serious comorbidities [10]. One Canadian study exploring loneliness amongst community-dwelling older adults found that $43.1 \%$ of older adults had experienced loneliness at least some of the time in the preceding week [11]. Factors associated with increased loneliness included having fair or poor health, changes to daily routine, and having a high concern for the pandemic [11]. These factors may be experienced differently by older adults with cancer, potentially exacerbating the impact of the COVID-19 pandemic on this patient population. With no clear ending of the COVID-19 pandemic in sight, understanding the psychosocial impact of the COVID-19 pandemic on older adults with cancer is crucial to provide patient- and family-centered care to this patient population.

In the face of the COVID-19 pandemic, older adults with cancer face intersecting vulnerabilities related to the physical effects of the virus, cancer-system changes, and the potentially isolating impacts of public health measures. The culmination of these effects on older adults warrants exploration as clinicians look to support older adults with cancer and prepare for future health crises. The purpose of this review is to synthesize the literature surrounding the psychosocial impact and coping strategies of older adults with cancer during the COVID-19 pandemic. Understanding how the pandemic has impacted older adults with cancer will help clinicians support them during subsequent waves of this pandemic, as well as plan for future pandemics.

\section{Methods}

To conduct this rapid review, we followed systematic review methodology and the updated preferred reporting items for systematic reviews and meta-analysis statement [12]. In alignment with best evidence on rapid review methods [13,14], we have streamlined the review process to rapidly produce information that is accessible to clinicians and decisionmakers by limiting to publications in English only, limiting the search time frame, and having one reviewer for abstracts and data abstraction with a second reviewer ensuring abstraction is completed in a timely manner.

\subsection{Inclusion Criteria}

- Peer-reviewed primary research of either qualitative, quantitative, or mixed-methods design.

- Published in the English language.

- Published since 2020 (which coincides with the start of the pandemic).

- Focused solely on older adults or those with a mean/median age of $\geq 65$.

\subsection{Exclusion Criteria}

- Expert opinions, editorials, case reports/case studies, gray literature, and secondary research.

\subsection{Information Sources and Search}

We conducted a comprehensive search strategy for this rapid review through consultation with an experienced health sciences librarian. The electronic databases searched included: (1) MEDLINE, (2) Embase (3) CINAHL, (4) PsychINFO. We did not search the gray literature as we felt it would not add additional value. The results were imported into Covidence [15] systematic review software to facilitate the screening of abstracts and full text. The detailed search conducted in MEDLINE is outlined in the Supplemental Material (Listing S1).

\subsection{Study Selection}

Since title and abstract screening were performed by one reviewer, we conducted training before screening, developed detailed inclusion/exclusion criteria, and held regular meetings to discuss any ongoing concerns. The review of the full texts was also conducted by one reviewer and verified by a second reviewer. The senior author $(\mathrm{KH})$ resolved any conflicts. Figure 1 represents the PRISMA flow diagram outlining the study selection. 


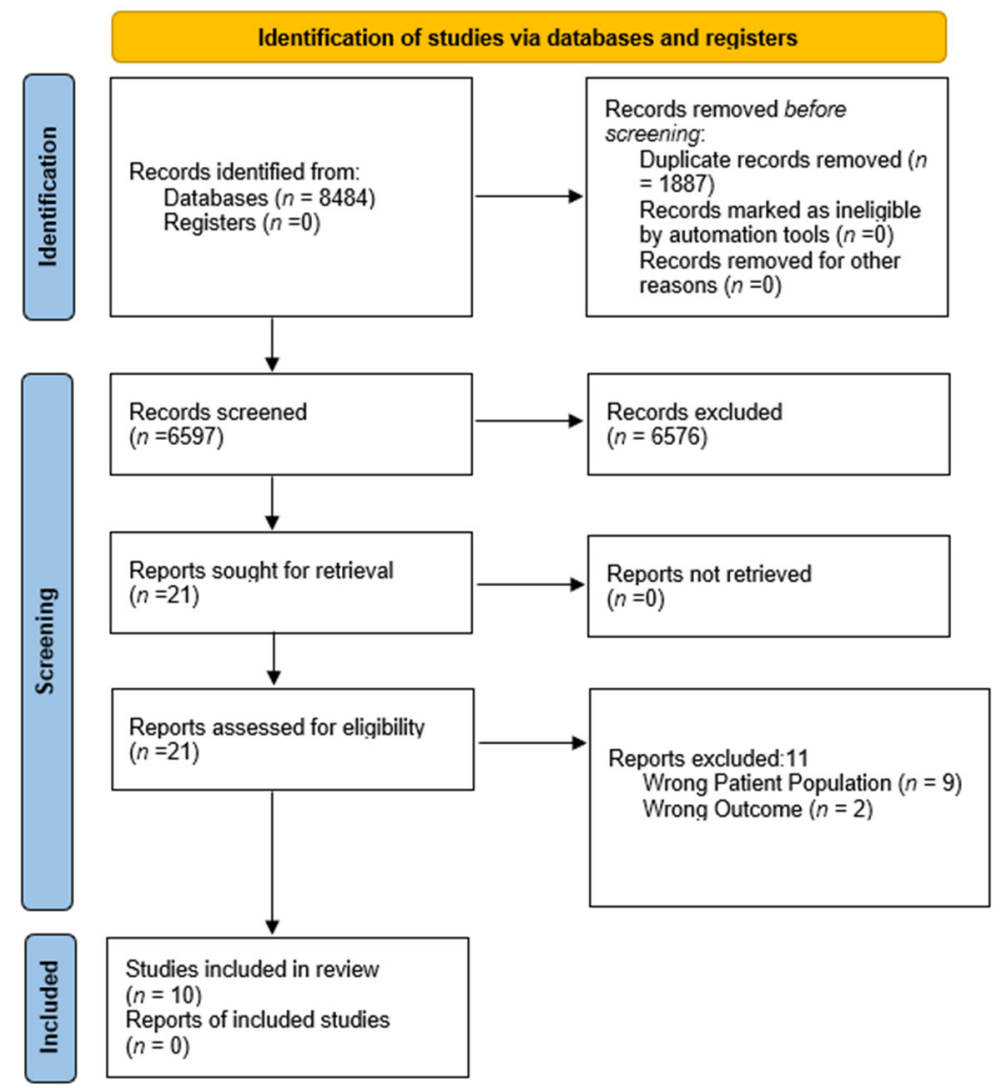

Figure 1. PRISMA flow diagram.

\subsection{Data Abstraction}

Data were collected using a standardized form in MS Excel, which included study characteristics (e.g., author, country, year, duration of data collection, and design), patient characteristics (e.g., target population and sample size, cancer diagnosis), aims of the study, outcomes along with corresponding outcome measures, and the study findings.

\subsection{Quality Assessment}

Critical appraisal of the included studies was assessed using validated quality assessment tools appropriate for the study design. The Joanna Briggs Institute (JBI) critical appraisal tool [16] was used for qualitative studies; the mixed methods appraisal tool (MMAT) [17] was employed to assess mixed-method studies, and cross-sectional studies were appraised using NIH study quality assessment tool $[18,19]$. One reviewer completed the critical appraisal process with results verified by a second reviewer. Discrepancies were resolved by the senior author $(\mathrm{KH})$. The detailed quality assessment can be found in the Supplemental Material (Table S1).

\subsection{Data Synthesis}

To summarize the literature, we narratively synthesized the study findings by mapping the results across the following key areas: (1) impact of COVID-19 on quality of life (QoL), (2) concerns related to COVID-19, (3) coping with the impact of COVID-19, and (4) recommendations for future care. Due to the methodological heterogeneity of the included literature, a meta-analysis was not considered to be an appropriate method of data synthesis.

\section{Results}

Of the 6597 articles screened, ten met the inclusion criteria. They included six quantitative cross-sectional surveys [20-25], three qualitative studies [26-28], and one study 
of mixed-method design [29]. Based on the quality assessment, six studies were of moderate quality $[20,22,24,26,28,29]$, with three being good $[21,23,25]$ and one study rated as poor [27]. The cross-sectional observational surveys assessed various facets of psychosocial well-being, including anxiety [20], QoL [20-23], and perceived change in attitudes and coping strategies $[24,25]$. Semi-structured $[27,28]$ and structured interviews [26] were conducted to ascertain fears and concerns [26,28], changes in behavior and lifestyle [26,27], coping behaviors $[27,28]$, and recommendations for cancer care [28] within the context of COVID-19. The included mixed-method study explored the coping strategies adopted by older adults with cancer both via a Brief-COPE questionnaire and a semi-structured interview [29]. A detailed description of the included studies is outlined in Table 1.

The results are organized into the following themes: (1) impact of COVID-19 on quality of life (QoL), (2) concerns related to COVID-19, (3) coping with the impact of COVID-19, and (4) recommendations for future care.

Figure 2 contains a visual presentation of the psychosocial impact of COVID-19 on older adults with cancer, including the factors associated with reduced QoL, major concerns amongst the population, and the adopted coping strategies.

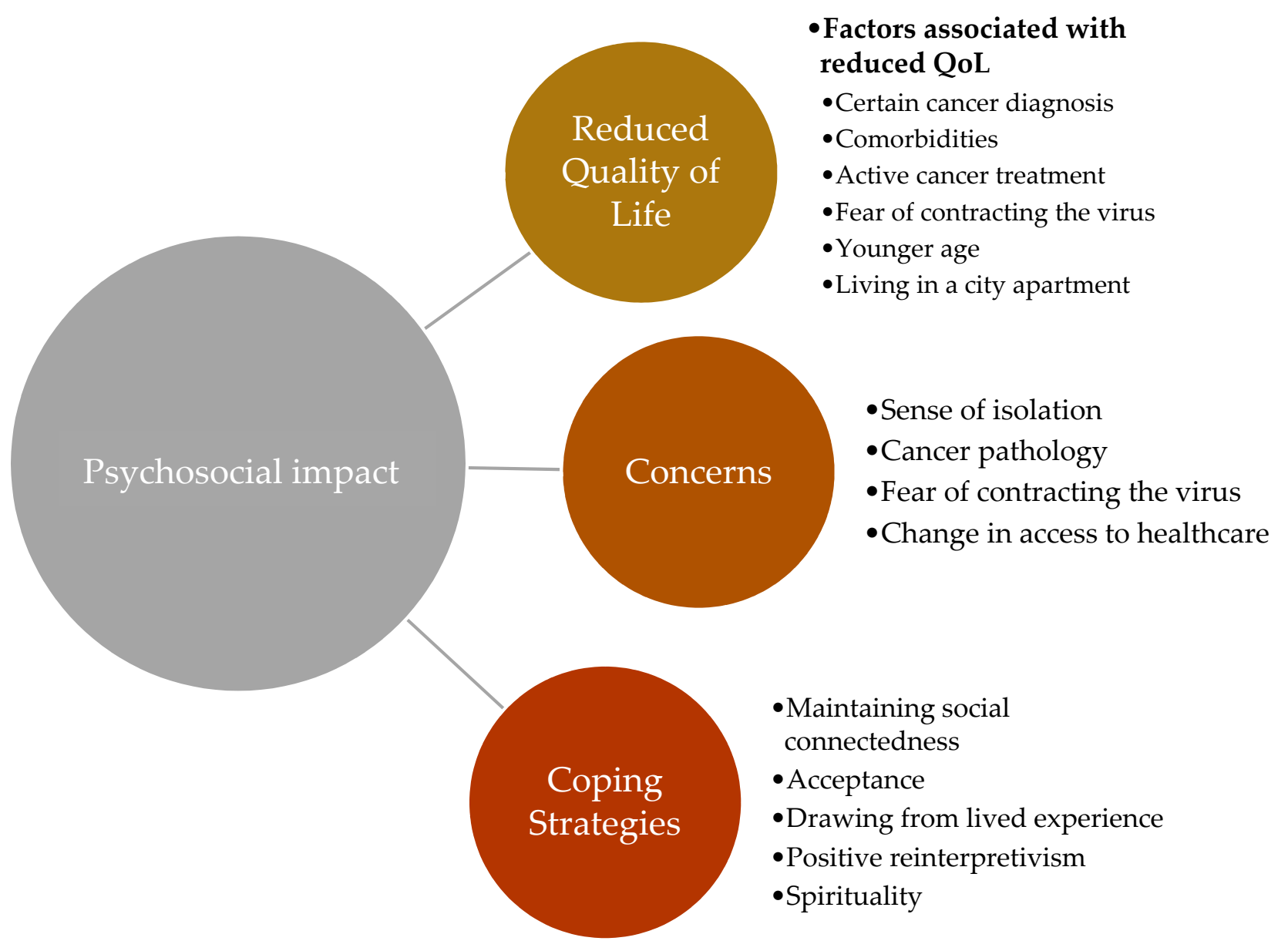

Figure 2. Psychosocial Impact of COVID-19 among older adults with cancer. 
Table 1. Description of the study characteristic, participant details, objective, and results

\begin{tabular}{|c|c|c|c|c|c|c|c|c|c|}
\hline $\begin{array}{c}\text { Author/ } \\
\text { Year/Country }\end{array}$ & $\begin{array}{l}\text { Duration of Data } \\
\text { Collection }\end{array}$ & $\begin{array}{c}\text { Design- } \\
\text { Quant/Qual }\end{array}$ & $\begin{array}{c}\text { Sample Size } \\
(n)\end{array}$ & Age (Years) & $\begin{array}{c}\text { Females } \\
(\%)\end{array}$ & $\begin{array}{c}\text { Cancer } \\
\text { Diagnosis } \\
\end{array}$ & Aim & $\begin{array}{c}\text { Outcomes and Outcomes } \\
\text { Measures }\end{array}$ & Results ** \\
\hline $\begin{array}{c}\text { Baffert } 2021[20] \\
\text { France }\end{array}$ & $\begin{array}{l}\text { May } 2020 \text { to the } \\
\text { beginning of } \\
\text { June } 2020\end{array}$ & $\begin{array}{c}\text { Quant } \\
\text { Cross-sectional } \\
\text { survey }\end{array}$ & $n=189$ & $\begin{array}{c}\text { Age } \\
\text { range- } 61-70\end{array}$ & $60 \%$ & $\begin{array}{l}\text { Lung, breast, and } \\
\text { colorectal cancer }\end{array}$ & $\begin{array}{l}\text { To evaluate anxiety, } \\
\text { HRQOL during the } \\
\text { COVID-19 pandemic, and } \\
\text { to assess the } \\
\text { non-psychological } \\
\text { consequences on quality of } \\
\text { life and satisfaction } \\
\text { with care. }\end{array}$ & $\begin{array}{l}\text { Anxiety-GAD-7 * } \\
\text { QoL-SF-12 * }\end{array}$ & $\begin{array}{l}11.1 \% \text { showed } \\
\text { anxiety. Mental } \\
\text { health } \\
\text { deteriorated } \\
(p<0.0001) .\end{array}$ \\
\hline $\begin{array}{l}\text { Bartels } 2021 \text { [21] } \\
\text { Netherlands }\end{array}$ & $\begin{array}{l}\text { Within two years } \\
\text { before the start } \\
\text { and during the } \\
\text { COVID-19 } \\
\text { lockdown }\end{array}$ & $\begin{array}{c}\text { Quant } \\
\text { Cross-sectional } \\
\text { online survey }\end{array}$ & $n=169$ & $\begin{array}{c}\text { Median } \\
\text { age-68 } \\
\text { (range 38-92) }\end{array}$ & $38 \%$ & Bone metastases & $\begin{array}{l}\text { To evaluate the effect of } \\
\text { societal COVID-19 } \\
\text { measures on changes in } \\
\text { quality of life and } \\
\text { emotional functioning of } \\
\text { patients with metastatic } \\
\text { bone disease }\end{array}$ & $\begin{array}{c}\text { QoL-BPI, } \\
\text { EORTC-C15-PAL, } \\
\text { EORTC-BM22, and } \\
\text { EQ5D-3L * }\end{array}$ & $\begin{array}{c}\text { Decrease in } \\
\text { general QoL } \\
\text { (72.4 to } 68.7, \\
p=0.007) ; \\
\text { increase in feeling } \\
\text { isolated (18\% } \\
\text { before and } 67 \% \\
\text { during lockdown) }\end{array}$ \\
\hline $\begin{array}{l}\text { Jeppesen } 2021 \text { [22] } \\
\text { Denmark }\end{array}$ & $\begin{array}{c}15 \text { May } 2020 \text { to } 29 \\
\text { May } 2020\end{array}$ & $\begin{array}{c}\text { Quant } \\
\text { Cross-sectional } \\
\text { cohort survey }\end{array}$ & $n=4571$ & Mean age -66 & $60 \%$ & $\begin{array}{l}\text { Breast cancer and } \\
\text { incurable cancer }\end{array}$ & $\begin{array}{l}\text { To investigate QoL for } \\
\text { patients with cancer, either } \\
\text { receiving active treatment } \\
\text { or in a follow up program } \\
\text { during the COVID-19 } \\
\text { pandemic with focus on } \\
\text { emotional functioning }\end{array}$ & $\begin{array}{c}\text { HRQOL-EORTC } \\
\text { QLQ-C30* }\end{array}$ & $\begin{array}{l}\text { No clinically } \\
\text { significant } \\
\text { differences in } \\
\text { global QoL and } \\
\text { emotional } \\
\text { function }(E F) \\
\text { scores }\end{array}$ \\
\hline $\begin{array}{c}\text { Koinig } 2021 \text { [23] } \\
\text { Austria }\end{array}$ & $\begin{array}{c}20 \text { April } 202018 \\
\text { June } 2020\end{array}$ & $\begin{array}{c}\text { Quant } \\
\text { Cross-sectional } \\
\text { online survey }\end{array}$ & $n=240$ & Mean age -67 & $46 \%$ & $\begin{array}{l}\text { Solid tumor and } \\
\text { hematological } \\
\text { malignancy }\end{array}$ & $\begin{array}{l}\text { To study cancer patients' } \\
\text { perception of the } \\
\text { COVID-19 pandemic and } \\
\text { its impact on their } \\
\text { everyday life during the } \\
\text { lockdown }\end{array}$ & $\begin{array}{l}\text { HRQOL-EORTC } \\
\text { QLQ-C30* }\end{array}$ & $\begin{array}{l}\text { No clinically } \\
\text { significant } \\
\text { differences in } \\
\text { physical, role, } \\
\text { emotional, or } \\
\text { social functioning, } \\
\text { or of global QOL }\end{array}$ \\
\hline $\begin{array}{l}\text { Büssing } 2021 \text { [24] } \\
\text { Germany }\end{array}$ & $\begin{array}{l}\text { May to June 2020, } \\
\text { (sample 1) and } \\
\text { September to } \\
\text { November 2020 } \\
\text { (sample 2) }\end{array}$ & $\begin{array}{c}\text { Quant } \\
\text { Cross-sectional } \\
\text { online survey }\end{array}$ & $\begin{array}{c}n=292 \\
(\text { sample } 1) \\
n=221 \\
\text { (sample 2) }\end{array}$ & $\begin{array}{l}\text { Mean age-- } \\
66.7 \pm 10.8\end{array}$ & $20.1 \%$ & $\begin{array}{c}\text { Prostate cancer, } \\
\text { larynx tumours, } \\
\text { and } \\
\text { nasal/paranasal } \\
\text { tumours }\end{array}$ & $\begin{array}{l}\text { To analyze the change in } \\
\text { patients' perceptions, fear, } \\
\text { worries, and emotional } \\
\text { adaptation between waves } \\
1 \text { and } 2 \text { of the pandemic }\end{array}$ & $\begin{array}{l}\text { Perceived changes- } \\
\text { 12-item short version of the } \\
\text { perceptions of change scale } \\
\text { Well-being-WHO-5* } \\
\text { Perceived daily life } \\
\text { affections-NAS* } \\
\text { Meaning in life-MLQ* } \\
\text { Indicators of } \\
\text { spirituality-SpREUK } \\
\text { questionnaire Awe and } \\
\text { gratitude-GrAw-7* }\end{array}$ & $\begin{array}{l}\text { Perception of } \\
\text { change and } \\
\text { indicators of } \\
\text { spirituality lower } \\
\text { in wave } 2 \\
(p=0.060)\end{array}$ \\
\hline
\end{tabular}


Table 1. Cont.

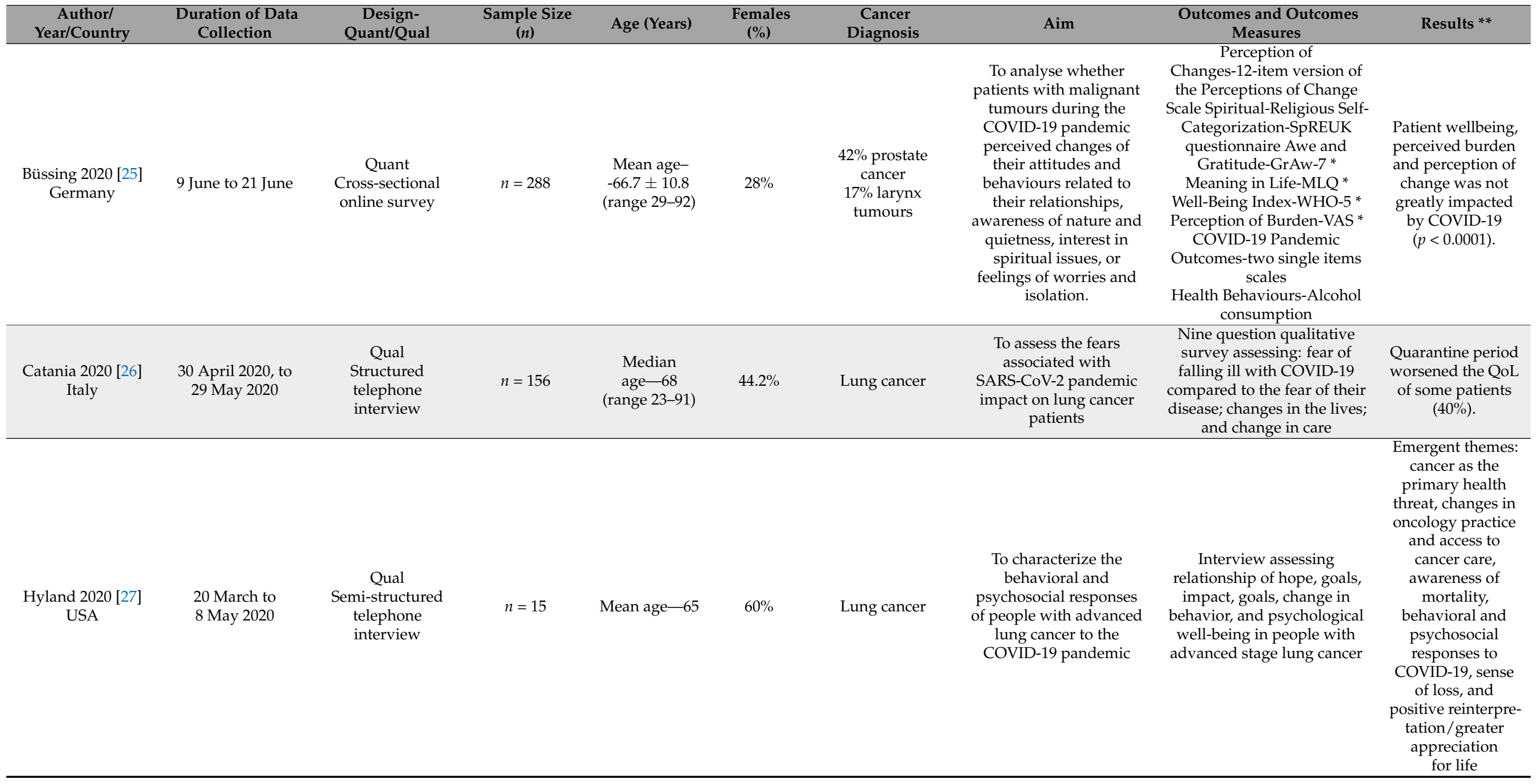


Table 1. Cont.

\begin{tabular}{|c|c|c|c|c|c|c|c|c|c|}
\hline $\begin{array}{c}\text { Author/ } \\
\text { Year/Country }\end{array}$ & $\begin{array}{l}\text { Duration of Data } \\
\text { Collection }\end{array}$ & $\begin{array}{c}\text { Design- } \\
\text { Quant/Qual }\end{array}$ & $\begin{array}{l}\text { Sample } \\
\text { Size }(n)\end{array}$ & Age (Years) & $\begin{array}{c}\text { Females } \\
(\%)\end{array}$ & $\begin{array}{c}\text { Cancer } \\
\text { Diagnosis }\end{array}$ & Aim & $\begin{array}{c}\text { Outcomes and Outcomes } \\
\text { Measures }\end{array}$ & Results ** \\
\hline $\begin{array}{l}\text { Haase } 2021 \text { [28] } \\
\quad \text { Canada }\end{array}$ & June and July 2020 & $\begin{array}{c}\text { Qual } \\
\text { Semi-structured } \\
\text { telephone } \\
\text { interviews }\end{array}$ & $n=30$ & $\begin{array}{l}\text { Mean } \\
\text { age-72.1 } \\
\text { years (range } \\
\text { 63-83) }\end{array}$ & $57 \%$ & $\begin{array}{l}\text { Breast and } \\
\text { colorectal cancer }\end{array}$ & $\begin{array}{l}\text { To report reflections on the } \\
\text { pandemic shared by older } \\
\text { adult cancer survivors and } \\
\text { to understand their } \\
\text { suggestions for suitable } \\
\text { resources and care delivery } \\
\text { methods }\end{array}$ & $\begin{array}{l}\text { Six questions assessing } \\
\text { concerns, coping, and } \\
\text { changes; suggestions for } \\
\text { future coping strategies and } \\
\text { delivery of care }\end{array}$ & $\begin{array}{l}\text { Accepted COVID } \\
\text { restrictions, } \\
\text { coping through } \\
\text { positive } \\
\text { reinterpretation }\end{array}$ \\
\hline $\begin{array}{c}\text { Galica } 2021 \text { [29] } \\
\text { Canada }\end{array}$ & NR & $\begin{array}{c}\text { Qual + Quant } \\
\text { Cross-sectional } \\
\text { survey } \\
\text { Semi-structured } \\
\text { telephone } \\
\text { interviews }\end{array}$ & $n=30$ & $\begin{array}{c}\text { Mean } \\
\text { age-72.1 } \\
\text { (range 63-83) }\end{array}$ & $57 \%$ & $\begin{array}{l}\text { Breast and } \\
\text { colorectal cancer }\end{array}$ & $\begin{array}{l}\text { To understand coping } \\
\text { among older cancer } \\
\text { survivors }\end{array}$ & $\begin{array}{l}\text { Coping (quantitative } \\
\text { data)-Brief-COPE } \\
\text { questionnaire. } \\
\text { (qualitative data) Telephone } \\
\text { interview conducted to } \\
\text { ascertain coping before and } \\
\text { during the pandemic along } \\
\text { with individual coping } \\
\text { strategies }\end{array}$ & $\begin{array}{l}\text { Emergent themes: } \\
\text { (1) drawing on } \\
\text { lived experiences, } \\
\text { (2) redeploying } \\
\text { coping strategies, } \\
\text { and (3) } \\
\text { complications of } \\
\text { cancer } \\
\text { survivorship in a } \\
\text { pandemic. }\end{array}$ \\
\hline
\end{tabular}

${ }^{*}$ NR—-not reported; GAD-7—-generalized anxiety disorder screener; OoL—quality of life; HROOL—health-related quality of life; SF-12—12-item short-form health survey; BPI—brie pain inventory; EORTC-C15-PAL and EORTC-BM22 - European Organization for Reserch and Treatment of Cancer quality of life questionnaires; EQ5D-3L-Euro-QoL five-dimensional instrument of Well-being In NAS - q a ic of where available. 


\subsection{Impact of COVID-19 on Quality of Life (QoL)}

The reviewed studies aimed to assess several aspects of psychosocial and emotional wellbeing, including anxiety [20], QoL, emotional functioning [20-23], and well-being and meaning in life [24,25]. Variability in psychosocial outcomes were reported across studies.

The surveys conducted to ascertain levels of anxiety and changes in perceived psychological well-being in patients with cancer during the lockdown suggested lower levels of anxiety (GAD-7 = $3.2 \pm 4.5)$ in areas minimally affected by COVID-19 [20]. This change met the level of minimal clinical important difference (MCID), which is estimated at 4 points on the GAD-7 total score [30]. Büssing et al. indicated a decrease in the prevalence of depressive states between the first lockdown and the second (35\% vs. $31 \%$ respectively), although this failed to reach statistical significance but is considered clinically significant (estimate of 1 or more points is proposed as MCID) [24,25,31].

Variations in the QoL levels collected only during the pandemic and those comparing pre- versus during pandemic scores were observed. Both qualitative and quantitative literature conducted during the pandemic suggested a decrease in general QoL [21,26] and emotional functioning [20] during the COVID-19 lockdown and quarantine period. Interestingly, pre- versus during COVID-19 pandemic comparisons conducted by Jeppesen et al. [22] and Koining et al. [23] revealed that the global QoL and emotional functioning ascertained through EORTC QLQ-C30 were not significantly altered by the pandemic, which can be considered clinically significant (MCID estimates of 5-14 points) [32].

The included studies detail several relationships between the COVID-19 pandemic and psychosocial health. Being a woman (gender) was a risk factor for anxiety and distress induced by the pandemic $(p<0.03)[20,22,23]$. Higher global QoL, emotional function, and wellbeing was correlated with increasing age [22], specifically, in patients aged $>60$ years $(p=0.01)[19,24]$. Those with a cancer diagnosis of brain tumors, cervical cancers, and thoracic cancers $(p$-value < 0.05) [22]; those with several comorbidities [22]; patients receiving medical cancer treatment [21], especially those receiving oral treatment [25]; those living alone $(p<0.05),[22]$; and those residing in city apartments $(p=0.01)$ [20] fared poorer on psychosocial measures [22]. Jeppesen et al. [22] suggested that employed patients had a higher global Qol score, while Baffert et al. [20] found the same in retired individuals $(p=0.04)$.

\subsection{Concerns Related to COVID-19}

Exploration of psychosocial wellbeing uncovered several concerns, such as loneliness, sense of frustration, concerns regarding their cancer diagnosis and treatment, fear of contracting the coronavirus, access to healthcare services, change in the pre-pandemic social structure, interruption of patients' normal life, and a sense of uncertainty [21,22,26,27]. According to one study, before the pandemic, $18 \%$ of patients experienced some degree of isolation, with a steep increase to $67 \%$ during the lockdown [21].

Fears surrounding disease progression and healthcare access during the pandemic were at the fore. Patients varied in the degree to which they expressed COVID-19 related concerns across studies. Three studies concluded that more than half of their participants expressed worry about being infected by the coronavirus and having a complicated course of COVID-19 [21,22,24]. However, older adults with cancer were balancing their fear of the pandemic with their ongoing fears related to their cancer [27]; 79\% of patients in one study reported being more afraid of their cancer than of COVID-19 [26]. Interestingly, those with more severe side effects and short-term cancer diagnosis focused on cancerrelated concerns, whereas patients with long-term cancer diagnosis ( $>12$ months) and those receiving ongoing treatment emphasized the threat of COVID-19 [26,27].

Patients had mixed feeling towards COVID-19-related social-distancing policies [27], with one study reporting $58 \%$ of participants were irritated by statements made about the dangers of a COVID-19 infection [24]. Older cancer survivors felt restricted by the pandemic due to the change in pre-pandemic social interaction, including the inability to travel or engage in formerly enjoyed social activities [18]. 
Concerns about change in oncology practices and access to health care were expressed by $49 \%$ of study participants [21], with $9 \%$ of patients refraining from consulting a doctor or visiting the hospital due to fear of contracting the virus [22]. Despite the fear, a majority of patients living with cancer understood the cruciality of continuing cancer treatment [27], heeding their health (80\%), and keeping up with their scheduled appointments (78\%) [23].

Several predictors of manifested fears and concerns towards COVID-19 were identified. Factors associated with increased distress related to COVID-19 included being a woman (gender) (55\%) $(p<0.001)$, presence of comorbidities $(24 \%)$, being unpartnered, having received radiotherapy or surgery for lung cancer $(30 \%)$, actively receiving intravenous treatment $(72 \%)(p=0.02)$, or receiving oral treatment not in their residence $(90 \%)$, and being younger than 60 or aged $60-70(p<0.001)[23,26,27]$.

\subsection{Coping with the Impact of COVID-19}

Older adults employed numerous coping strategies across the COVID-19 pandemic. Common coping strategies included maintaining social connection $[24,25,27,29]$, redeploying previous coping strategies [27,29], and engaging with spirituality [24,25,27].

Despite the isolating circumstances imposed by the COVID-19 pandemic and the associated public health measures, older adults maintained social connectedness as a means of coping $[25,27,29]$. Büssing et al. [24,25] found participants reported more intense relationships with partners, family, and friends, along with spirituality, as a means of coping at two time points during the pandemic [24,25]. Means of maintaining social connectedness included using technology to engage with loved ones [29] and continuing to see family and friends in-person under certain perceived-safe conditions [27]. Quantitative analysis revealed that the most common strategies of older adult cancer survivors included acceptance $(96.7 \%)$, self-distraction $(93.3 \%)$, and taking action $(93.3 \%)$ [27,29]. Older adult cancer survivors drew from their cancer and non-cancer experiences and redeployed coping strategies in the face of the current pandemic [23,29]. Hyland et al. [27] discussed how older adults with cancer used positive reinterpretation and spritituality as an important coping measure, which included focusing on the positives in life and appreciating what you have.

\subsection{Recommendations for Future Care}

Numerous studies discussed recommendations for supporting older adults with cancer during the COVID-19 pandemic. Büssing et al. [25] advocated for further spiritual care and psychotherapy as a means of supporting older adults with cancer's resilience. Mindfulness training was recommended to clinicians with a focus on preventing ruminating on negative thoughts and instead supporting positive reinterpretation [24]. Considering the importance of maintaining social connectedness as a means of coping, Bartels et al. [21] recommended facilitating safe connection for patients and their caregivers, suggesting strategies such as peer-to-peer contact and online mental health interventions.

One of the included studies looked specifically at recommendations for supporting older adult cancer survivors across the pandemic. Haase et al. [28] conducted semistructured, qualitative interviews with older adult cancer survivors during the pandemic. Informed by these interviews and the perspectives of older adults, recommendations for supporting older adult cancer survivors were proposed. First, healthcare providers should provide older adults with enhanced baseline information during appointments [28]. Second, healthcare providers should support the involvement of caregivers in survivorship care [28]. Third, providers should support older adults through the transition to virtual care and the further integration of technology into healthcare [28]. Finally, individuals felt people now better appreciated the value of personal protective equipment, and its use would likely be sustained beyond the pandemic [28]. 


\section{Discussion}

We conducted this rapid review to summarize the available literature pertaining to psychosocial well-being within the context of the COVID-19 pandemic amongst older adults with cancer. The results from the included studies were consolidated under four domains: (1) impact of COVID-19 on QoL, (2) concerns related to COVID-19, (3) coping with the impact of COVID-19, and (4) recommendations for future care. Numerous factors such as, being younger than 60 years of age [21]; being a woman [19]; having several co-morbidities [19,22]; receiving active treatment, especially oral therapies [21,25]; and living in city apartments $[19,21]$ were associated with poorer psychosocial wellbeing and increased fears and concerns towards COVID-19.

Interestingly, the literature reported inconsistent findings regarding QoL. Studies comparing pre-pandemic QoL scores to those collected during the pandemic show no change in the QoL and emotional functioning scores [22,23]. Baffert et al. [20] also suggested, in a region wherein the rate of infection was limited, anxiety post lockdown was low. These results were consistent with findings among patients with multiple sclerosis who reported no increase in anxiety and depression in the six months preceding the COVID-19 lockdown and during it [33]. Two possible factors could justify the results; firstly, those with a cancer diagnosis were possibly better equipped to assimilate to the COVID restriction due to their continual accommodation to a restrictive lifestyle [23]. Secondly, the increased social proximity with those within their household [23] and enhanced opportunity to allocate more time to physical activity could possibly contribute towards alleviating emotional distress [34,35]. It is noteworthy to mention that physical exercise is considered an important intervention to counteract both the physical and psychosocial impacts amongst both older adults with cancer and those without [10].

The surveys and qualitative studies conducted during the lockdown period alone suggest reduced QoL and emotional functioning [20,21,26]. In the included papers, depressive states were observed during both waves of the lockdown in May and September [24,25]. Similar reports of anxiety, depressive symptoms, and psychological distress during the lockdown were gathered from patients with breast cancer, ovarian cancer, thyroid cancer, and lymphoma [36-39]. The heterogeneity in cancer diagnosis, disease stage, and patient population highlights the unmet psychological needs across the cancer continuum amidst the pandemic [40,41]. Anxiety levels were higher in women [20], which is consistent with gender being a risk factor for anxiety in patients with cancer in general [42]. Similar studies conducted with healthy participants reported female gender as being significantly associated with higher levels of stress, anxiety, depression, and more negative psychological effects of COVID-19 as well [43]. Participants identifying as women expressed increased concern related to COVID-19 as they felt a responsibility for their loved ones and feared passing on the virus to them [26]. During the pandemic, heightened levels of anxiety, fears, and depression have also been observed amongst healthy community-dwelling adults as well [10]. Given the predisposing vulnerabilities of older adults with cancer, these psychosocial concerns may have more deleterious side effects [10].

Major concerns amongst older adults with cancer included an increased sense of isolation [21] and changes in access to healthcare services [21,22]. Both cancer and COVID19 were prominent concerns of older adults with cancer; however the degree of concern varied across studies $[21,22,24,26,27]$. Change in cancer care, especially postponements or modifications of therapies and scheduled visits with the oncology team, were a prevalent source of distress as it meant a failure to return to normal $[26,27]$. Loneliness adversely affects cognitive function in older adults and confers a greater risk of poor physical and mental health [44]. Therefore, clinicians must recognize the isolation faced by older adults with cancer in order to counteract the negative impact on cognitive function [45]. Setting up mental health facilities to mitigate pandemic-induced psychological impacts of any future eventualities can be of merit $[10,46]$.

Contrary to discourse surrounding the vulnerability of older adults, age was a reported strength in coping. Older adults above the age of 65 had better QoL scores and relatively fewer 
fears surrounding COVID-19 compared to their younger counterparts [20,22,23,26]. Drawing from lived experiences enabled older adults to conceptualize and cope with the current pandemic [29]. Koinig et al. [23] reported similar findings, observing that older adults with cancer were well equipped to adapt to the restrictions imposed by COVID-19, as they had previously adapted to the changes associated with their cancer diagnosis. Although the COVID-19 pandemic has caused significant disruption to older adults, so too did their cancer diagnosis. Older adults demonstrated resilience by maintaining social connectedness with family and friends either virtually [17] or through physically distant interactions [19]. Accepting the restrictions and positively reinterpreting the current social restrictions helped older adults' express greater appreciation for their relationships, with some seeing this as an opportunity to spend more time at home $[17,19]$. This psychological resilience can be explained to some extent by the 'sense of coherence theory', which incorporates comprehensibility (ability to understand and integrate), manageability (ability to navigate and manage), and meaningfulness (sense-making) to support the better navigation of life stressors [47]. This perceived sense of coherence in the event of a new health threat is a strong predictor of health status among older adults $[48,49]$. This is especially beneficial as this resilience elucidates the ability of older adults to utilize both internal and external resources to facilitate successful coping with stressors, contrary to the societal discourse surrounding age-related weakness [50].

The present review is not without limitations. The results pooled from the included studies present a level of heterogeneity in cancer diagnosis and homogeneity in ethnicity and education within the study sample. Due to social distancing guidelines, some surveys were administered online. Hence, those with limited access to eHealth resources were at a possible disadvantage. The surveys lacked COVID-specific questionnaires to measure QoL. This provides an opportunity for the development of a tool within this realm. There is a need for future studies to have an ethnically and socioeconomically diverse sample and to employ a standardized COVID-19 specific tool to measure QoL.

\section{Conclusions}

This review, to the best of our knowledge, is the first to summarize the available evidence on the psychosocial impact of COVID-19 on older adults with cancer. The results pertaining to the change in QoL were inconsistent. Older adults were concerned by changes in their cancer care, loneliness, their disease progression, and contracting the coronavirus. Coping strategies included leaning on personal relationships, maintaining spirituality, accepting the changes associated with the pandemic, engaging in positive interpretation, and drawing on previous experience. The factors affecting the psychosocial wellbeing outlined in the current review, coupled with the suggestions for future care, can help tailor and reorganize oncology practice during the current pandemic and for any subsequent global health crises.

Supplementary Materials: The following are available online at https:/ /www.mdpi.com/article/10 .3390/curroncol29020053/s1, Listing S1: Search Strategy and Table S1: Quality Assessment.

Author Contributions: Conceptualization, R.V., H.M.K. and K.R.H.; methodology, R.V., H.M.K. and K.R.H.; investigation, R.V., H.M.K. and K.R.H.; data curation, R.V., H.M.K. and K.R.H.; writingoriginal draft preparation, R.V., H.M.K. and K.R.H.; writing-review and editing, R.V., H.M.K. and K.R.H.; supervision, K.R.H. All authors have read and agreed to the published version of the manuscript.

Funding: This research received no external funding.

Conflicts of Interest: The authors declare no conflict of interest.

\section{References}

1. Kuderer, N.M.; Choueiri, T.K.; Shah, D.P.; Shyr, Y.; Rubinstein, S.M.; Rivera, D.R.; Shete, S.; Hsu, C.-Y.; Desai, A.; de Lima Lopes, G., Jr. Clinical impact of COVID-19 on patients with cancer (CCC19): A cohort study. Lancet 2020, 395, 1907-1918. [CrossRef]

2. Lee, L.Y.; Cazier, J.B.; Starkey, T.; Turnbull, C.; The UK Coronavirus Monitoring Project Team; Kerr, R.; Middleton, G. COVID-19 mortality in patients with cancer on chemotherapy or other anticancer treatments: A prospective cohort study. Lancet 2020, 395, 1919-1926. [CrossRef] 
3. $\quad$ Liang, W.; Guan, W.; Chen, R.; Wang, W.; Li, J.; Xu, K.; Li, C.; Ai, Q.; Lu, W.; Liang, H. Cancer patients in SARS-CoV-2 infection: A nationwide analysis in China. Lancet Oncol. 2020, 21, 335-337. [CrossRef]

4. Tian, Y.; Qiu, X.; Wang, C.; Zhao, J.; Jiang, X.; Niu, W.; Huang, J.; Zhang, F. Cancer associates with risk and severe events of COVID-19: A systematic review and meta-analysis. Int. J. Cancer 2021, 148, 363-374. [CrossRef] [PubMed]

5. Wu, Z.; McGoogan, J.M. Characteristics of and important lessons from the coronavirus disease 2019 (COVID-19) outbreak in China: Summary of a report of 72314 cases from the Chinese Center for Disease Control and Prevention. JAMA 2020, 323, 1239-1242. [CrossRef] [PubMed]

6. Patt, D.; Gordan, L.; Diaz, M.; Okon, T.; Grady, L.; Harmison, M.; Markward, N.; Sullivan, M.; Peng, J.; Zhou, A. Impact of COVID19 on cancer care: How the pandemic is delaying cancer diagnosis and treatment for American seniors. JCO Clin. Cancer Inform. 2020, 4, 1059-1071. [CrossRef]

7. Vanni, G.; Tazzioli, G.; Pellicciaro, M.; Materazzo, M.; Paolo, O.; Cattadori, F.; Combi, F.; Papi, S.; Pistolese, C.A.; Cotesta, M. Delay in breast cancer treatments during the first COVID-19 lockdown. A multicentric analysis of 432 patients. Anticancer. Res. 2020, 40, 7119-7125. [CrossRef]

8. Nekhlyudov, L.; Duijts, S.; Hudson, S.V.; Jones, J.M.; Keogh, J.; Love, B.; Lustberg, M.; Smith, K.C.; Tevaarwerk, A.; Yu, X. Addressing the needs of cancer survivors during the COVID-19 pandemic. J. Cancer Surviv. 2020, 14, 1-6. [CrossRef]

9. Krok-Schoen, J.L.; Pisegna, J.L.; BrintzenhofeSzoc, K.; MacKenzie, A.R.; Canin, B.; Plotkin, E.; Boehmer, L.M.; Shahrokni, A. Experiences of healthcare providers of older adults with cancer during the COVID-19 pandemic. J. Geriatr. Oncol. 2021, 12, 190-195. [CrossRef]

10. Dubey, S.; Biswas, P.; Ghosh, R.; Chatterjee, S.; Dubey, M.J.; Chatterjee, S.; Lahiri, D.; Lavie, C.J. Psychosocial impact of COVID-19. Diabetes Metab. Syndr. Clin. Res. Rev. 2020, 14, 779-788. [CrossRef]

11. Savage, R.D.; Wu, W.; Li, J.; Lawson, A.; Bronskill, S.E.; Chamberlain, S.A.; Grieve, J.; Gruneir, A.; Reppas-Rindlisbacher, C.; Stall, N.M. Loneliness among older adults in the community during COVID-19: A cross-sectional survey in Canada. BMJ Open 2021, 11, e044517. [CrossRef] [PubMed]

12. Moher, D.; Shamseer, L.; Clarke, M.; Ghersi, D.; Liberati, A.; Petticrew, M.; Shekelle, P.; Stewart, L.A. Preferred reporting items for systematic review and meta-analysis protocols (PRISMA-P) 2015 statement. Syst. Rev. 2015, 4, 1. [CrossRef] [PubMed]

13. Khangura, S.; Polisena, J.; Clifford, T.J.; Farrah, K.; Kamel, C. Rapid review: An emerging approach to evidence synthesis in health technology assessment. Int. J. Technol. Assess. Health Care 2014, 30, 20-27. [CrossRef] [PubMed]

14. Dobbins, M. Rapid review guidebook. Natl. Collab. Cent. Method Tools 2017, 13, 25.

15. Innovation, V.H. Covidence Systematic Review Software. Available online: http://www.covidence.org/ (accessed on 15 December 2021).

16. Lockwood, C.; Munn, Z.; Porritt, K. Qualitative research synthesis: Methodological guidance for systematic reviewers utilizing meta-aggregation. JBI Evidence Implementation 2015, 13, 179-187. [CrossRef]

17. Hong, Q.N.; Fàbregues, S.; Bartlett, G.; Boardman, F.; Cargo, M.; Dagenais, P.; Gagnon, M.-P.; Griffiths, F.; Nicolau, B.; O'Cathain, A. The Mixed Methods Appraisal Tool (MMAT) version 2018 for information professionals and researchers. Educ. Inf. 2018, 34, 285-291. [CrossRef]

18. National Heart, L.; Institute, B. Quality assessment tool for before-after (pre-post) studies with no control group. In Systematic Evidence Reviews and Clinical Practice Guidelines; National Institutes of Health: Washington, DC, USA, 2014.

19. National Heart, Lung, and Blood Institute. Quality Assessment Tool for Observational Cohort and Cross-Sectional Studies. 2017. Available online: https:/ / www.nhlbi.nih.gov/health-topics/study-quality-assessment-tools (accessed on 15 December 2021).

20. Baffert, K.-A.; Darbas, T.; Lebrun-Ly, V.; Pestre-Munier, J.; Peyramaure, C.; Descours, C.; Mondoly, M.; Latrouite, S.; Bignon, E.; Nicouleau, S. Quality of life of patients with cancer during the COVID-19 pandemic. In Vivo 2021, 35, 663-670. [CrossRef]

21. Bartels, M.; Gal, R.; van der Velden, J.; Verhoeff, J.; Verlaan, J.; Verkooijen, H. Impact of the COVID-19 pandemic on quality of life and emotional wellbeing in patients with bone metastases treated with radiotherapy: A prospective cohort study. Clin. Exp. Metastasis 2021, 38, 209-217. [CrossRef]

22. Jeppesen, S.S.; Bentsen, K.K.; Jørgensen, T.L.; Holm, H.S.; Holst-Christensen, L.; Tarpgaard, L.S.; Dahlrot, R.H.; Eckhoff, L. Quality of life in patients with cancer during the COVID-19 pandemic-A Danish cross-sectional study (COPICADS). Acta Oncol. 2021, 60, 4-12. [CrossRef]

23. Koinig, K.A.; Arnold, C.; Lehmann, J.; Giesinger, J.; Köck, S.; Willenbacher, W.; Weger, R.; Holzner, B.; Ganswindt, U.; Wolf, D. The cancer patient's perspective of COVID-19-induced distress-A cross-sectional study and a longitudinal comparison of HRQOL assessed before and during the pandemic. Cancer Med. 2021, 10, 3928-3937. [CrossRef]

24. Büssing, A.; Recchia, D.R.; Hübner, J.; Walter, S.; Büntzel, J.; Büntzel, J. Tumor patients' fears and worries and perceived changes of specific attitudes, perceptions and behaviors due to the COVID-19 pandemic are still relevant. J. Cancer Res. Clin. Oncol. 2021, 147, 1673-1683. [CrossRef] [PubMed]

25. Büssing, A.; Hübner, J.; Walter, S.; Gießler, W.; Büntzel, J. Tumor Patients' Perceived Changes of Specific Attitudes, Perceptions, and Behaviors Due to the COVID-19 Pandemic and Its Relation to Reduced Wellbeing. Front. Psychiatry 2020, $11,574314$. [CrossRef] [PubMed]

26. Catania, C.; Spitaleri, G.; Del Signore, E.; Attili, I.; Radice, D.; Stati, V.; Gianoncelli, L.; Morganti, S.; De Marinis, F. Fears and Perception of the Impact of COVID-19 on Patients with Lung Cancer: A Mono-Institutional Survey. Front. Oncol. 2020, 10, 2237. [CrossRef] [PubMed] 
27. Hyland, K.A.; Jim, H.S. Behavioral and psychosocial responses of people receiving treatment for advanced lung cancer during the COVID-19 pandemic: A qualitative analysis. Psycho-Oncology 2020, 29, 1387-1392. [CrossRef]

28. Haase, K.R.; Kain, D.; Merchant, S.; Booth, C.; Koven, R.; Brundage, M.; Galica, J. Older survivors of cancer in the COVID-19 pandemic: Reflections and recommendations for future care. J. Geriatr. Oncol. 2021, 12, 461-466. [CrossRef]

29. Galica, J.; Liu, Z.; Kain, D.; Merchant, S.; Booth, C.; Koven, R.; Brundage, M.; Haase, K.R. Coping during COVID-19: A mixed methods study of older cancer survivors. Support. Care Cancer 2021, 29, 3389-3398. [CrossRef]

30. Toussaint, A.; Hüsing, P.; Gumz, A.; Wingenfeld, K.; Härter, M.; Schramm, E.; Löwe, B. Sensitivity to change and minimal clinically important difference of the 7-item Generalized Anxiety Disorder Questionnaire (GAD-7). J. Affect. Disord. 2020, 265, 395-401. [CrossRef]

31. Cheung, D.S.T.; Takemura, N.; Chau, P.H.; Ng, A.Y.M.; Xu, X.; Lin, C.C. Exercise levels and preferences on exercise counselling and programming among older cancer survivors: A mixed-methods study. J. Geriatr. Oncol. 2021, 12, 1173-1180. [CrossRef]

32. Maringwa, J.; Quinten, C.; King, M.; Ringash, J.; Osoba, D.; Coens, C.; Martinelli, F.; Reeve, B.; Gotay, C.; Greimel, E. Minimal clinically meaningful differences for the EORTC QLQ-C30 and EORTC QLQ-BN20 scales in brain cancer patients. Ann. Oncol. 2011, 22, 2107-2112. [CrossRef]

33. Capuano, R.; Altieri, M.; Bisecco, A.; d’Ambrosio, A.; Docimo, R.; Buonanno, D.; Matrone, F.; Giuliano, F.; Tedeschi, G.; Santangelo, G. Psychological consequences of COVID-19 pandemic in Italian MS patients: Signs of resilience? J. Neurol. 2021, 268, 743-750. [CrossRef]

34. Callow, D.D.; Arnold-Nedimala, N.A.; Jordan, L.S.; Pena, G.S.; Won, J.; Woodard, J.L.; Smith, J.C. The mental health benefits of physical activity in older adults survive the COVID-19 pandemic. Am. J. Geriatr. Psychiatry 2020, 28, 1046-1057. [CrossRef]

35. Carriedo, A.; Cecchini, J.A.; Fernandez-Rio, J.; Méndez-Giménez, A. COVID-19, psychological well-being and physical activity levels in older adults during the nationwide lockdown in Spain. Am. J. Geriatr. Psychiatry 2020, 28, 1146-1155. [CrossRef]

36. Juanjuan, L.; Santa-Maria, C.A.; Hongfang, F.; Lingcheng, W.; Pengcheng, Z.; Yuanbing, X.; Yuyan, T.; Zhongchun, L.; Bo, D.; Meng, L. Patient-reported outcomes of patients with breast cancer during the COVID-19 outbreak in the epicenter of China: A cross-sectional survey study. Clin. Breast Cancer 2020, 20, e651-e662. [CrossRef]

37. Frey, M.K.; Fowlkes, R.K.; Badiner, N.M.; Thomas, C.; Christos, P.J.; Martin, P.; Gamble, C.; Balogun, O.D.; Cardenes, H.; Holcomb, K.; et al. Gynecologic oncology care during the COVID-19 pandemic at three affiliated New York City hospitals. Gynecol. Oncol. 2020, 159, 470-475. [CrossRef]

38. Romito, F.; Dellino, M.; Loseto, G.; Opinto, G.; Silvestris, E.; Cormio, C.; Guarini, A.; Minoia, C. Psychological distress in outpatients with lymphoma during the COVID-19 pandemic. Front. Oncol. 2020, 10, 1270. [CrossRef]

39. Falcone, R.; Grani, G.; Ramundo, V.; Melcarne, R.; Giacomelli, L.; Filetti, S.; Durante, C. Cancer care during COVID-19 era: The quality of life of patients with thyroid malignancies. Front. Oncol. 2020, 10, 1128. [CrossRef]

40. Fernando, A. Mental health and cancer: Why it is time to innovate and integrate-A call to action. Eur. Urol. Focus 2020, 6, 1165-1167. [CrossRef]

41. Younger, E.; Smrke, A.; Lidington, E.; Farag, S.; Ingley, K.; Chopra, N.; Maleddu, A.; Augustin, Y.; Merry, E.; Wilson, R. Health-related quality of life and experiences of sarcoma patients during the COVID-19 pandemic. Cancers 2020, $12,2288$. [CrossRef]

42. Zeynalova, N.; Schimpf, S.; Setter, C.; Yahiaoui-Doktor, M.; Zeynalova, S.; Lordick, F.; Loeffler, M.; Hinz, A. The association between an anxiety disorder and cancer in medical history. J. Affect. Disord. 2019, 246, 640-642. [CrossRef]

43. Li, S.; Wang, Y.; Xue, J.; Zhao, N.; Zhu, T. The impact of COVID-19 epidemic declaration on psychological consequences: A study on active Weibo users. Int. J. Environ. Res. Public Health 2020, 17, 2032. [CrossRef]

44. Zhong, B.-L.; Chen, S.-L.; Tu, X.; Conwell, Y. Loneliness and cognitive function in older adults: Findings from the Chinese longitudinal healthy longevity survey. J. Gerontol. Ser. B 2017, 72, 120-128. [CrossRef]

45. Yang, R.; Wang, H.; Edelman, L.S.; Tracy, E.L.; Demiris, G.; Sward, K.A.; Donaldson, G.W. Loneliness as a mediator of the impact of social isolation on cognitive functioning of Chinese older adults. Age Ageing 2020, 49, 599-604. [CrossRef]

46. Mrabet, J. COVID-19 Pandemic: A Curse or a Blessing? Psychol. Educ. J. 2020, 57, 1146-1154.

47. Antonovsky, A. Health, stress, and coping. New Perspect. Ment. Phys. Well-Being 1979, 12-37.

48. Forbes, D.A. Enhancing mastery and sense of coherence: Important determinants of health in older adults. Geriatr. Nurs. 2001, 22, 29-32. [CrossRef] [PubMed]

49. McKinlay, A.; Fancourt, D.; Burton, A. A qualitative study about the mental health and wellbeing of older adults in the UK during the COVID-19 pandemic. BMC Geriatr. 2021, 21, 439. [CrossRef]

50. Mc Gee, S.L.; Höltge, J.; Maercker, A.; Thoma, M.V. Evaluation of the revised Sense of Coherence scale in a sample of older adults: A means to assess resilience aspects. Aging Ment. Health 2018, 22, 1438-1447. [CrossRef] 